\title{
Cyclopolymerization. IX. Radiation-Induced Solid-State Polymerization of $\mathrm{N}$-Octadecyldimethacrylamide
}

\author{
Toshiyuki KoDAIRA and Makio SAKAI \\ Department of Industrial Chemistry, Faculty of Engineering, \\ Fukui University, Fukui 910, Japan.
}

(Received October 11, 1978)

\begin{abstract}
Solid-state cyclopolymerization of $N$-octadecyldimethacrylamide(ODMA) has been investigated in an attempt to clarify the effect of its long-chain substituent on the polymerization, as compared with the reported polymerization of $N$-substituted dimethacrylamides(RDMA) which have small substituents. The polymerizability of ODMA has been found to be higher than that of RDMA in the solid state, especially in the postirradiation polymerization, though the former is comparable with the latter in the solution polymerization. $\mathrm{X}$ ray diffraction studies have revealed that poly(ODMA) is a partially crystalline polymer, in contrast to the poly(RDMA) which is amorphous. However, the other results are similar to those obtained in the polymerization of RDMA, viz., the sigmoid time-conversion curve, higher polymerizability in the liquid state than in the solid state, structural characteristics of the polymer, and the fact that the ratedetermining step of the solid-state polymerization of ODMA is an intramolecular cyclization reaction. Consequently, it has been suggested that the polymerization of ODMA proceeds under the influence of crystalline structure, probably due to the ordered arrangement originating from its long octadecyl group, but some destruction of the structure is necessary for the polymerization.

KEY WORDS Radiation Polymerization / Solid-State Polymerization / Cyclopolymerization / N-Octadecyldimethacrylamide / Substituent Effect / X-Ray Diffraction / ESR / Propagating Radical /
\end{abstract}

The effect of a long alkyl chain in the solid-state polymerization of a homologous series of compounds has been investigated by several authors. A high rate of the solid-state polymerization is observed in long-chain alcohol esters of methacrylic ${ }^{1,2}$ and acrylic ${ }^{3}$ acid. The dependence of the polymerization behavior of maleimide derivatives ${ }^{4}$ on the length of $N$-alkyl substituents in the solid state has been found. Both results suggest the fundamental role of the ordered structure, which originates from the long alkyl chain, in the polymerization of these monomers. Further, the formation of partially crystalline polymers has been reported in the case of the polymerization of vinyl stearate ${ }^{5}$ in the solid state, where vinyl monomers usually afford amorphous polymers.

The solid-statepolymerization of $N$-substituted dimethacrylamides(RDMA) which have smaller groups, e.g., methyl(MDMA), propyl(PrDMA), benzyl(BDMA), and phenyl(PhDMA) groups, as substituents has already been reported. ${ }^{6-8}$ The structure of poly(RDMA) formed in the solid state ${ }^{7.8}$ is slightly different from that formed in the liquid state,${ }^{7-10}$ though the crystallographic study showed that the polymers are amorphous. In addition, the rate-determining step of the solid-state polymerization of RDMA has been determined to be an intramolecular cyclization reaction irrespective of the substituents on nitrogen. ${ }^{8,11}$ Since the reported results on the monomers having a long alkyl chain mentioned above show that they have quite different polymerization behaviors from their homologues, the polymerization of $\mathrm{N}$-octadecyldimethacrylamide(ODMA) in the solid state has been undertaken in an attempt to clarify the effect of its long-<smiles>C=C(C)C(=O)N(CC)C(=O)C(=C)C</smiles> 
chain substituent on the solid-state cyclopolymerization, in connection with the polymerization results of RDMA.

\section{EXPERIMENTAL}

\section{Materials}

Synthesis of ODMA. ODMA was prepared according to the procedure described for RDMA. ${ }^{12}$ The crystalline substance obtained was dissolved in benzene and the solution was decolored by mixing with active carbon, removing it by filtration and repeating the procedure eight times. The solid residue, after evaporation of benzene, was recrystallized three times from the solvent system. It consisted of 50 parts of ethyl alcohol and one part of benzene and afforded a white crystal which melts at 40 $41^{\circ} \mathrm{C}$. The supposed structure was confirmed by NMR and IR spectra and results of elementary analyses.

Anal. Calcd for $\mathrm{C}_{26} \mathrm{H}_{47} \mathrm{NO}_{2}$ : C, $76.98 \% ; \mathrm{H}, 11.67 \%$; N, $3.45 \%$. Found: C, $77.25 \%$; H, $11.96 \%$; N, 3.57\%.

All solvents were purified by the usual techniques.

\section{Polymerization}

Polymerization was carried out in sealed glass tubes under vacuum. After the polymerization under given conditions the contents of the tube were poured into ethyl alcohol and kept at $25-30^{\circ} \mathrm{C}$ with a small amount of hydroquinone added. The system was allowed to stand for several hours at the temperature and filtered through a sintered glass crucible. Operation at the storage temperature is required to get reproducible results in the polymer yield, which was determined gravimetrically. The polymers for the spectroscopic and molecular weight measurements described below were subjected to the extraction, because they are contaminated with a small amount of monomers. The mixed solvents used for the recrystallization of ODMA were added to the polymer and the system was allowed to stand overnight. The solvents were removed by decantation and the fresh solvents were again added to the residual polymer. After 10 extractions by this procedure, the polymer was dried under reduced pressure. Irradiation was undertaken by using ${ }^{60} \mathrm{Co} \gamma$ rays at a given temperature for the in-source polymerization and at $-78^{\circ} \mathrm{C}$ for the postirradiation polymerization.

\section{Measurements}

All the spectra and X-ray diffraction diagrams were recorded as described in a previous work. ${ }^{8}$

The molecular weight of the poly(ODMA) was determined on a Corona 117 molecular weight apparatus, using benzene as the solvent at $40^{\circ} \mathrm{C}$.

\section{RESULTS}

\section{Solid-State Polymerization of ODMA}

Sigmoid time-conversion curves obtained in the in-source polymerization of ODMA at 0 and $30^{\circ} \mathrm{C}$ are shown in Figure 1. ODMA polymerized rapidly

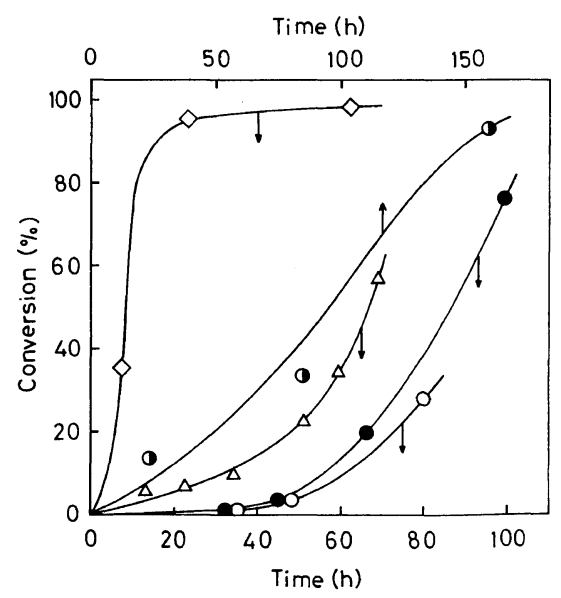

Figure 1. Solid-state in-source polymerization of ODMA: $\diamond$, temp, $30^{\circ} \mathrm{C}$, dose rate, $0.92 \mathrm{Mradh}^{-1} ; \triangle$, temp, $0^{\circ} \mathrm{C}$, dose rate, $0.41 \mathrm{Mrad} \mathrm{h}^{-1}$. Reported data on $\mathrm{RDMA}^{8}$ were also shown for comparison with the permission of the publishers (Hüthig and Wepf Verlag, Basel): 1 , MDMA, temp, $30^{\circ} \mathrm{C}$, dose rate, $0.83 \mathrm{Mrad}$ $\mathrm{h}^{-1}$;, PrDMA, temp, $0^{\circ} \mathrm{C}$, dose rate, $0.41 \mathrm{Mrad} \mathrm{h}^{-1}$; O, BDMA, temp, $0^{\circ} \mathrm{C}$, dose rate, $0.41 \mathrm{Mrad} \mathrm{h}^{-1}$. Data for PhDMA were not illustrated, but its polymerization rate is much slower than that of MDMA.

in comparison with PrDMA and BDMA, even though the latter two monomers have melting points lower than ODMA. The polymerization rate of ODMA at $30^{\circ} \mathrm{C}$ is apparently much higher than that of MDMA and PhDMA, but the large differences between the melting points of ODMA, and the latter two substituents (Table I) do not allow any conclusion about their polymerizability. The temperature dependence of the in-source polymerization of ODMA is illustrated in Figure 2. The polymer yield 
Tabel I. Melting points and results of postirradiation polymerization of RDMA ${ }^{\mathrm{a}}$

\begin{tabular}{|c|c|c|c|c|}
\hline \multirow{2}{*}{ Monomer } & $\mathrm{mp}$ & \multirow{2}{*}{ Time } & \multirow{2}{*}{$\frac{\text { Temp }}{{ }^{\circ} \mathrm{C}}$} & \multirow{2}{*}{$\frac{\text { Yield }}{\%}$} \\
\hline & ${ }^{\circ} \mathrm{C}$ & & & \\
\hline MDMA & & $48 \mathrm{~h}$ & 30 & 3.8 \\
\hline MDMA & $90.5-91$ & $48 \mathrm{~h}$ & 50 & 4.4 \\
\hline MDMA & & $48 \mathrm{~h}$ & 70 & 3.6 \\
\hline PhDMA & $80.5-81$ & $48 \mathrm{~h}$ & 50 & 0.8 \\
\hline PrDMA & $\sim 26$ & 218 day & 0 & trace \\
\hline BDMA & $29-30$ & 53 day & 0 & 2.8 \\
\hline
\end{tabular}

${ }^{\text {a }}$ Irradiated at $-78^{\circ} \mathrm{C}$ for $30 \mathrm{~h}$ with a dose rate of 2.27 $\mathrm{Mrad} \mathrm{h}^{-1}$.

Reported data ${ }^{8}$ except the polymerization result of MDMA at $30^{\circ} \mathrm{C}$ were reproduced with the permission of the publishers (Hüthing and Wepf Verlag, Basel).

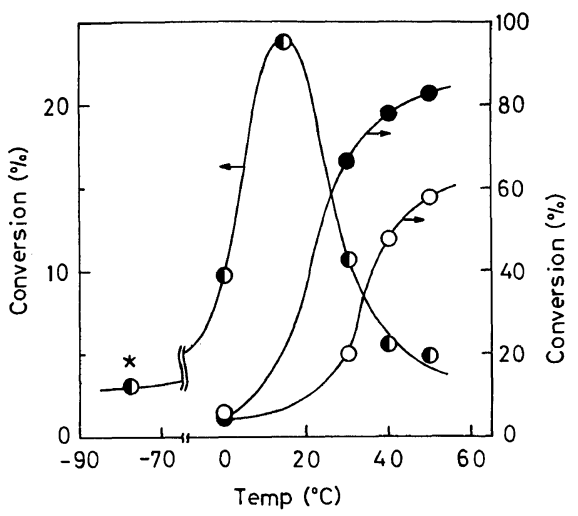

Figure 2. Effect of temperature on the polymerization of ODMA. In-source polymerization was irradiated with a dose rate of $0.39 \mathrm{Mrad} \mathrm{h}^{-1}$ for $10 \mathrm{~h}(\bigcirc)$ and for $20 \mathrm{~h}$ (O). Postirradiation polymerization (D) was done for $48 \mathrm{~h}$ at respective temperatures after the irradiation at $-78^{\circ} \mathrm{C}$ with a dose rate of $2.05 \mathrm{Mrad} \mathrm{h}^{-1}$ for $33 \mathrm{~h}$. * , This result is regarded as the in-source polymerization of ODMA at $-78^{\circ} \mathrm{C}$, but the polymer might be formed during the precipitation procedure.

increases rapidly with increasing temperature over the $20^{\circ} \mathrm{C}$ range below the melting point. The similar experiment for postirradiation polymerization revealed that the optimum temperature for the polymerization exists around $15^{\circ} \mathrm{C}$ (Figure 2). These results also show a higher polymerizability of ODMA than that of RDMA (Table I) in the postirradiation polymerization. On the other hand, the polymerization rate in benzene solution (Figure 3) is somewhat hither than that of RDMA,

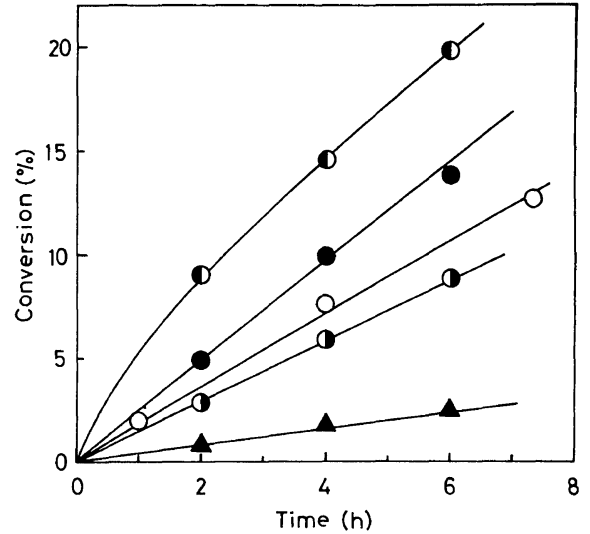

Figure 3. Solution polymerization of ODMA and RDMA in benzene: 0 , ODMA; O, PhDMA; $\bigcirc$, MDMA; О, BDMA; $\mathbf{A}$, PrDMA; [M], $1 \mathrm{~mol} \mathrm{dm}^{-3}$, [AIBN], $1.88 \times 10^{-2} \mathrm{~mol} \mathrm{dm}^{-3}$, temp, $60^{\circ} \mathrm{C}$. Data on RDMA $^{10}$ were reproduced for comparison with the permission of the publisher (The Society of Polymer Science, Japan).

but it is of a comparable order.

The molecular weights of the poly(ODMA) obtained under various conditions are summarized in Table II. Higher-molecular-weight polymers are formed in the liquid state than in the solid state when polymerization is carried out under simlilar conditions.

\section{Structure of Poly (ODMA)}

The repeating units which are expected in the poly(ODMA) are two cyclic structures, viz., five- and six-membered rings, and an uncyclized structure. The IR and ${ }^{1} \mathrm{H}$ NMR spectra of ODMA and its polymer are depicted in Figure 4. It is concluded that the poly(ODMA) does not contain any detectable pendent double bonds, because the absorption due to the stretching vibration of $\mathrm{C}=\mathrm{C}$ double bonds at $1630 \mathrm{~cm}^{-1}$ and the signal due to $\mathrm{CH}_{2}=\mathrm{C}<$ protons which are observed in the IR and NMR spectra of ODMA, respectively, could not be detected in those of poly(ODMA). The strong absorption at $1700 \mathrm{~cm}^{-1}$ and the weak signal at $1770 \mathrm{~cm}^{-1}$ in the IR spectrum of poly(ODMA) indicate that the main repeating cyclic structure is the five-membered imide ring. ${ }^{13}$ The analyses of the signal due to the NMR of $>\mathrm{N}-\mathrm{CH}_{2}-$ protons according to that of poly(RDMA $)^{7-10}$ show that the poly(ODMA) contains a small amount of six-membered rings. The proportion of six-membered rings to five-membered 
Table II. Molecular weights and contents of five-membered rings of poly(ODMA) formed by in-source polymerization

\begin{tabular}{|c|c|c|c|c|c|}
\hline Temp & Time & Dose rate & Yield & & $\begin{array}{c}\text { 5-Membered } \\
\text { ring }\end{array}$ \\
\hline${ }^{\circ} \mathrm{C}$ & $\mathrm{h}$ & $\operatorname{Mrad~h}^{-1}$ & $\%$ & & $\%$ \\
\hline 30 & 10 & 0.39 & 19.8 & - & 87.4 \\
\hline 30 & 20 & 0.39 & 66.1 & 4190 & 85.3 \\
\hline 40 & 20 & 0.39 & 77.3 & 13400 & 95.1 \\
\hline 50 & 10 & 0.39 & 57.6 & 14400 & 95.3 \\
\hline 50 & 20 & 0.39 & 82.6 & 12500 & 94.7 \\
\hline 0 & 52 & 0.41 & 29.1 & - & 88.4 \\
\hline 0 & 60 & 0.41 & 34.3 & 3290 & 85.0 \\
\hline 30 & 6 & 0.92 & 35.9 & 3430 & - \\
\hline 30 & 23 & 0.92 & 94.9 & 3320 & 87.7 \\
\hline 30 & 56 & 0.92 & 98.6 & $1830^{\mathrm{a}}$ & $86.6^{a}$ \\
\hline $15^{\mathrm{b}}$ & 48 & 2.05 & 23.8 & 3170 & 86.2 \\
\hline $60^{\mathrm{c}}$ & 6 & - & 19.5 & 4900 & 95.7 \\
\hline
\end{tabular}

a The values were determined for unextracted polymer, because the poly(ODMA) formed under the present conditions was not contaminated with monomer. Mol wt obtained after the extraction was 3200 .

b Postpolymerized after the irradiation at $-78^{\circ} \mathrm{C}$ for $33 \mathrm{~h}$.

c Solution polymerization in benzene: [M], $1 \mathrm{~mol} \mathrm{dm}{ }^{-3}$; [AIBN], $1.88 \times 10^{-2} \mathrm{~mol} \mathrm{dm}^{-3}$.

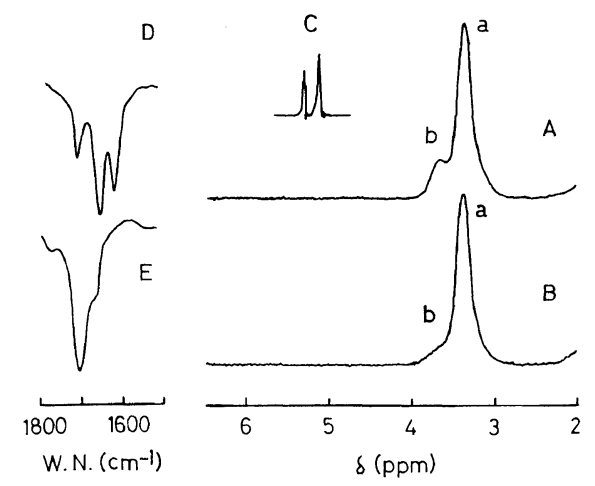

Figure 4. IR and ${ }^{1} \mathrm{H}$ NMR spectra of ODMA and poly(ODMA): A, poly(ODMA) formed in the solid state; $\mathrm{B}$, poly(ODMA) obtained in the liquid state; $\mathrm{C}, \mathrm{CH}_{2}=\mathrm{C}<$ protons of ODMA; D, stretching vibration of $\mathrm{C}=\mathrm{O}$ and $\mathrm{C}=\mathrm{C}$ dobule bonds of ODMA; $\mathrm{E}$, carbonyl absorption of poly(ODMA) formed in the solid state; a, $>\mathrm{N}-\mathrm{CH}_{2}-$ protons of five-membered ring; $b,>\mathrm{N}-\mathrm{CH}_{2}-$ protons of six-membered ring.

rings obtained from the signal areas at $\delta=3.39$ and $3.68 \mathrm{ppm}$ is larger in the polymer formed in the solid state than in the liquid state (Table II). This characteristic is also found for poly(RDMA).

\section{$X$-Ray Diffraction Studies}

$\mathrm{X}$-Ray diffraction studies have been carried out

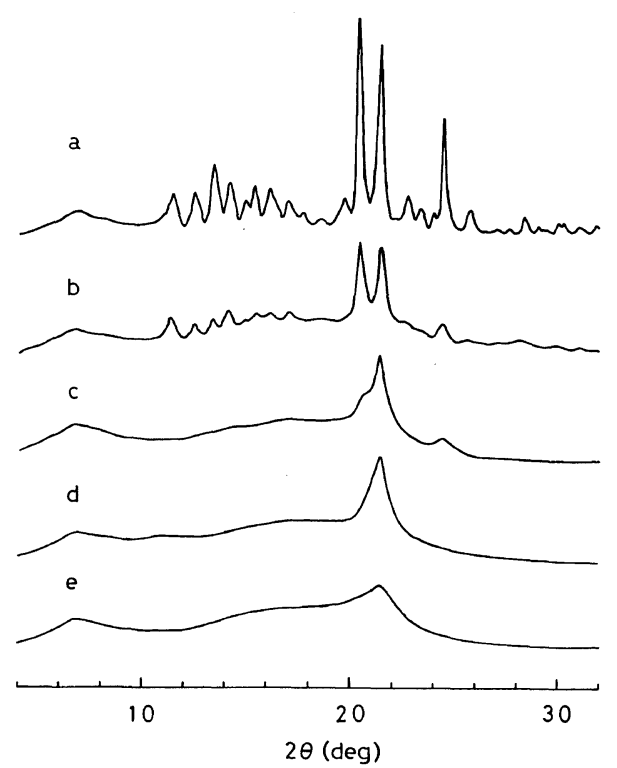

Figure 5. X-Ray diffraction diagrams observed during the course of the solid-state polymerization of ODMA: a, ODMA; b, $28.7 \%$ polymer content; c, $66.1 \%$ polymer content; $\mathrm{d}, 98.6 \%$ polymer content. The polymer contents were determined gravimetrically after the $\mathrm{X}$-ray diffraction measurements. Irradiated at $30^{\circ} \mathrm{C}$ with a dose rate of $0.39 \mathrm{Mrad} \mathrm{h}^{-1}$ for b and c, respectively, and with that of $0.92 \mathrm{Mrad} \mathrm{h}^{-1}$ for $\mathrm{d}$. e, polymer obtained in benzene solution. 
for unirradiated and irradiated ODMA.The results obtained are depicted in Figure 5. The diagrams show that most of the characteristic peaks of the monomer disappear rapidly as the irradiation dose increases, but a broad weak peak at $2 \theta=6.8^{\circ}$ and a sharp intense peak at $2 \theta=21.4^{\circ}$, which correspond to the spacings of 13.0 and $4.2 \AA$, respectively, remain even after the monomer is converted almost completely to polymer. Since the single intense line corresponding to a spacing of $4.2 \AA$, is similar to that observed in vinyl stearate ${ }^{5}$ and also in polymers derived from the vinyl stearate ${ }^{14}$ and long-chain alcohol esters of acrylic and methacrylic acid, ${ }^{15}$ the irradiated ODMA which has been converted to poly(ODMA) is considered to maintain an ordered structure due to paraffin-like crystallites. The diffuse $13 \AA$ reflection is not so easily interpreted. Poly(ODMA) formed in benzene solution also diffracts X-rays at $2 \theta=6.8$ and $21.4^{\circ}$, but the line width of the signal at $2 \theta=21.4^{\circ}$ is broader and the intensity of the peak is weaker than the poly(ODMA) obtained in the solid state. Bragg angles determined for irradiated RDMA showed that poly(RDMA) is amorphous. ${ }^{8}$

\section{Electron Spin Resonance Studies of Irradiated $O D M A$}

Various radical species were formed in the ODMA irradiated at $-196^{\circ} \mathrm{C}$. They disappear to leave finally the spectrum shown in Figure 6 when the irradiated system was treated under the conditions

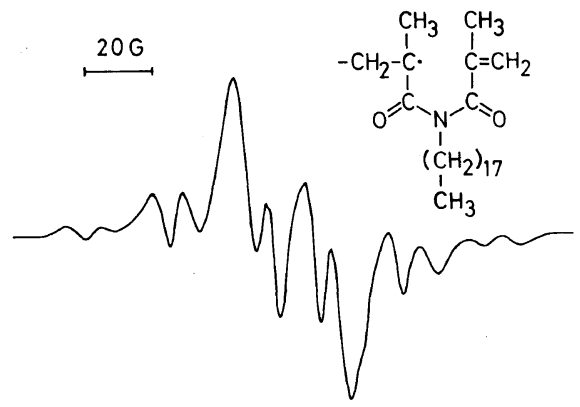

Figure 6. ESR spectrum of ODMA irradiated at $-196^{\circ} \mathrm{C}$ with a dose rate of $2.05 \mathrm{Mrad} \mathrm{h}^{-1}$ for $2 \mathrm{~h}$ and observed at room temperature after warming to $20^{\circ} \mathrm{C}$ for $16 \mathrm{~h}$.

described in the Figure. The spectrum is ascribed to the uncyclized radical, based upon the interpretation made for the ESR spectrum observed in the ir- radiated MDMA. ${ }^{11}$ As a result, the rate-determining step in the solid-state polymerization of ODMA is attributed to the intramolecular cyclization reaction, in agreement with $\mathrm{RDMA}^{8}{ }^{8}$ because the cyclized radical would be observed if the cyclization reaction were to proceeds rapidly.

\section{DISCUSSION}

The polymerizability of ODMA in the solid state is higher than that of RDMA in the postirradiation polymerization, whereas the former is rather comparable with the latter in solution (Table I and Figures 2 and 3). In the case of in-source polymerization, the polymerizability of ODMA could not be compared with MDMA and PhDMA because of the large difference in melting point between ODMA and the two monomers. But ODMA polymerizes faster than PrDMA and BDMA in spite of the fact that its melting point is higher than that of the latter two substituents (Figure 1). The results may be taken to imply that ODMA polymerizes under the influence of crystalline structure. In fact, X-ray diffraction studies revealed that the polymerization of ODMA in the solid state proceeds with a retention of orientation which can be ascribed to the ordered structure of its long alkyl chain. However, some results which suggest the polymerization in amorphous phase were also obtained during the investigation, e.g., the sigmoid shape of the time-conversion curves, the rapid increase in the rate of the in-source polymerization with increase in the temperature just below its melting point, and a higher molecular weight for the polymer formed in the liquid state than in the solid state. These apparent contradictions might be interpreted as follows. The polymerization of ODMA proceeds under the influence of ordered structure originating from its long hydrocabon chain, but some destruction in crystalline structure is necessary, especially in the region where the polymerization reaction occurs. The optimum polymerization temperature observed in the postirradiation polymerization suggests that the rigidity of the crystalline structure prevents the polymerization at lower temperature and the rapid disappearance of radicals trapped in the irradiated ODMA due to the molecular motion does not allow the polymerization to proceed to high conversions at higher temperatures. This consideration is supported by the decaying process of radicals trapped in 


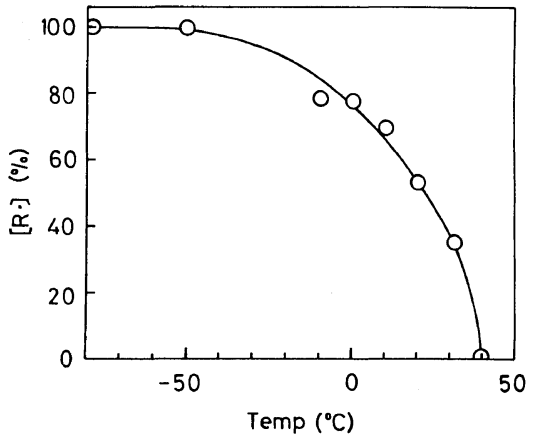

Figure 7. Variation of radical concentration [R - ] trapped in ODMA, which is expressed as the fraction (in $\%$ ) of radical detected at $-160^{\circ} \mathrm{C}$, immediately after the irradiation at $-78^{\circ} \mathrm{C}$ for $40 \mathrm{~h}$ with a dose rate of 2.05 $\mathrm{Mrad} \mathrm{h}^{-1}$. The radical concentrations at other temperatures were calculated based upon the spectra measured at $-160^{\circ} \mathrm{C}$ after the heat-treatment at each temperature for $20 \mathrm{~min}$.

ODMA, as is illustrated in Figure 7.

The result that a lower-molecular-weight polymer is obtained in the solid state than in the liquid state (Table II) means that the polymerization proceeds under the influence of ordered structure. But after the addition of several monomers, the propagating chain end cannot attack neighboring monomers, because of the restricted movement of propagating chain ends and ODMA molecules due to their long hydrocarbon substituents trapped in the crystalline lattice. Thus the ordered structure due to the long octadecyl group is in favor of the solid-state polymerization of ODMA in its initial stage, but after some while it becomes unfavorable. Further destruction of the crystalline structure is required to propagate to a high-molecular-weight polymer, as in the polymerization in the liquid state.
Acknowledgment. A part of this work was done under the Visiting Researchers' Program of Kyoto University Research Reactor Institute.

\section{REFERENCES}

1. G. Y. Hardy, K. Nyitrai, J. Varga, G. Kovacs, and N. Fedorova, J. Polym. Sci., C, 4, 923 (1964).

2. M. J. Bowden and J. H. O'Donnell, J. Polym. Sci., $A^{*} 1,7,1657$ (1969).

3. Y. Shibasaki and K. Fukuda, Abstracts, SPSJ 24th Symposium on Macromolecules, Osaka, November 6, 1975, p 607.

4. J. H. O'Donnell and R. D. Sothman, Makromol. Chem., 175, 833 (1974).

5. N. Morosoff, H. Morawetz, and B. Post, J. Am. Chem. Soc., 87, 3035 (1965).

6. M. Azori, N. A. Plate, G. D. Rudkovskaya, T. A. Sokolova, and V. A. Kargin, Vysokomol. Soedin., 8, 759 (1966).

7. G. B. Butler and G. R. Myers, J. Macromol. Sci., Chem., A5, 135 (1971).

8. T. Kodaira, M. Ni-imoto, F. Aoyama, and H. Yamaoka, Makromol. Chem., 179, 1791 (1978).

9. T. Kodaira and F. Aoyama, J. Polym. Sci., Polym. Chem. Ed., 12, 897 (1974).

10. T. Kodaira, F. Aoyama, K. Morishita, M. Tsuchida, and S. Nogi, Kobunshi Ronbunshu, 31, 682 (1974).

11. T. Kodaira, K. Morishita, H. Yamaoka, and H. Aida, J. Polym. Sci., Polym. Lett. Ed., 11, 347 (1973).

12. G. D. Rudkovskaya and T. A. Sokolova, Zh. Org. Khim., 2, 1220 (1966).

13. K. Nakanishi, "IR Absorption SpectroscopyPractical," Nankodo Publishing, Tokyo, 1960, p 52.

14. D. A. Lutz and P. Witnauer, J. Polym. Sci., B, 2, 31 (1964).

15. S. A. Greenberg and T. Alfrey, J. Am. Chem. Soc., 76, 6280 (1954). 